\begin{tabular}{|c|c|c|c|c|c|c|}
\hline \multirow{4}{*}{ Impact Factor: } & ISRA (India) & $=3.117$ & SIS (USA) & $=0.912$ & ICV (Poland) & $=6.630$ \\
\hline & ISI (Dubai, UAE & $=0.829$ & РИНЦ (Russia) & $=0.156$ & PIF (India) & $=1.940$ \\
\hline & GIF (Australia) & $=0.564$ & ESJI (KZ) & $=8.716$ & IBI (India) & $=4.260$ \\
\hline & JIF & $=1.500$ & SJIF (Morocco) & $=5.667$ & OAJI (USA) & $=0.350$ \\
\hline
\end{tabular}

\section{SOI: $1.1 /$ TAS DOI: $10.15863 /$ TAS International Scientific Journal Theoretical \& Applied Science}

p-ISSN: 2308-4944 (print) e-ISSN: 2409-0085 (online)

Year: 2019 Issue: $04 \quad$ Volume: 72

Published: $30.04 .2019 \quad$ http://T-Science.org

SECTION 26. Radio-technique. Electronics. Telecommunications.
QR - Issue

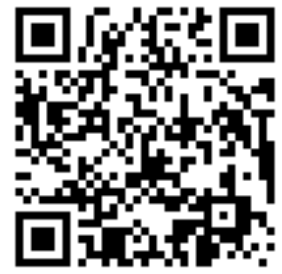

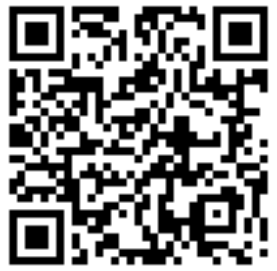

Sherzod Atadjanov

Head of the department for work with branches, assistant of the department "Audiovisual technologies",

Tashkent University of information technologies named after Muhammad al-Khwarizmi, Faculty of Telecommunications technologies, Tashkent, Uzbekistan, umb@tuit.uz

Aziza Tursunova assistant of the department "Audiovisual technologies", Tashkent, University of information technologies named after Muhammad al-Khwarizmi, Faculty of Telecommunications technologies, Tashkent, Uzbekistan, umb@tuit.uz

Abdunabi Ergashev

Head of educational and methodical management, senior teacher of the department "Software Information

Technologies", Tashkent University of information technologies named after Muhammad al-Khwarizmi,

Tashkent, Uzbekistan, tatuumb@mail.ru

Ravshan Indiaminov doctor of physical and mathematical sciences, professor Samarkand branch of Tashkent University of Information Technologies, Samarkand, Uzbekistan,

\title{
SIMULATION AND ANALYSIS OF HIGH-PRECISION ITERATIVE CODE WITH INCREASED EFFICIENCY
}

Abstract: In the article, based on computer simulation environment, a model of noise-resistant coding system was developed, which works on the basis of the algorithm of parallel-cascade high-precision coding and iterative decoding. A comparative analysis of the energy gain high-precision iterative algorithm with Gray coding algorithm is made. The results of modeling in Simulink error-correcting code and an iterative high-precision Gray code in digital transmission of information.

Key words: digital television, decoding, decoder, iteration, model.

Language: English

Citation: Atadjanov, S., Tursunova, A., Ergashev, A., \& Indiaminov, R. (2019). Simulation and analysis of highprecision iterative code with increased efficiency. ISJ Theoretical \& Applied Science, 04 (72), 421-429.

Soi: http://s-o-i.org/1.1/TAS-04-72-53 Doi: crossef https://dx.doi.org/10.15863/TAS.2019.04.72.53

\section{INTRODUCTION}

With a large-scale transition to digital television, ensuring high noise immunity of signals presented in digital form is an urgent task. When transmitting digital television signals on a point-to-point basis, there is always a possibility that the received signals contain errors.

In digital television (DTV) image quality is estimated using the probabilistic-energy characteristics (PEC). To date, in the field of digital communication, the development and implementation 


\begin{tabular}{|c|c|c|c|c|c|c|}
\hline \multirow{4}{*}{ Impact Factor: } & ISRA (India) & $=3.117$ & SIS (USA) & $=0.912$ & ICV (Poland) & $=6.630$ \\
\hline & ISI (Dubai, UAE & $=0.829$ & РИНЦ (Russia & $=\mathbf{0 . 1 5 6}$ & PIF (India) & $=1.940$ \\
\hline & GIF (Australia) & $=0.564$ & ESJI (KZ) & $=8.716$ & IBI (India) & $=4.260$ \\
\hline & JIF & $=1.500$ & SJIF (Morocco & $=5.667$ & OAJI (USA) & $=0.350$ \\
\hline
\end{tabular}

of new effective methods and algorithms that increase the noise immunity of digital signals are widely implemented [1].

But, basic principles that determine the properties and design of the optimal code have not yet been improved, allowing the system as a whole to achieve maximum noise immunity.

For example, in most parity-checking codes, you only need to add one character to the information sequence to detect the error, and in order for this code to correct a single error, for example, nine more information symbols will need to add seven more verification ones.

Thus, the redundancy of this code turns out to be very large, and the correcting ability is comparatively low.

Therefore, the scientific works and efforts of specialists in the field of noise-immune encoding have always been aimed at finding such codes and methods of encoding and decoding, which, with minimal redundancy, would provide the maximum correcting capability.

\section{MATERIALS AND METHODS}

A. NC model by the Gray method using MPSK modulation

In DTV, a noise-resistant coding (NC) system based on Gray code (Gray coding) is often used.

This method is used in multi-level modulation schemes to minimize the bit error rate by ordering the modulation symbols so that the binary signals of the adjacent symbols differ only by one bit.

Figure 1 shows the Gray coding model using MPSK (multiple phase shift keying, or $M$-ary phase shift keying, here $M$ is the modulation level) modulation developed in the Matlab 7.0 Simulink environment.

The novelty of the work is that computer modeling and research of PC processes is of great importance in the information and communication field. The simulation results allow analysis and investigation of many complex processes in the paths and channels with noise.
The model includes the following blocks:

- a block of a random number generator that produces a sequence of integers (serves as a source of digital signals);

- converter block Integer to Bit, converts each integer number into the corresponding binary signals;

- AWGN (additive white Gaussian noise) channel block, adds white Gaussian noise to the modulated data;

- MPSK demodulator, demodulates the main band and blocks the corrupted data.

- converter block Bit to Integer, this unit converts each binary representation of signals into a corresponding integer;

- Error Rate Calculation 1, compares the demodulated integer data with the original data, which gives statistics of symbolic errors. The output of the error rate calculation unit is a three-element vector containing the estimated error rate, the number of observed errors, and the amount of data processed.

- Error Rate Calculation 2, compares the demodulated binary data with the original binary data, which gives the statistics of the error bits.

\section{B. The error probability (BER-Bit Error Rate) for the Gray code}

When transmitting MPSK signals, the value of the bit error probability $P_{B}$ is less than or equal to the error probability for $P_{E}$ symbols, as well as for the transmission of MFSK signals.

For orthogonal signaling, the selection of one of the $(M-1)$ erroneous symbols is equally probable. When transmitting in the MPSK modulation, each signal vector is not equidistant from all the others.

Figure 2, a shows the octal solution space, where the decision areas are denoted by 8-digit symbols in the binary notation.

When the symbol (011) is transmitted and the error appears in it, the nearest neighboring characters, (010) and (100) are most likely. The probability of the transformation of the symbol (011) due to an error in the symbol (111) is relatively small. 


\begin{tabular}{|c|c|c|c|c|c|c|}
\hline \multirow{4}{*}{ Impact Factor: } & ISRA (India) & $=3.117$ & SIS (USA) & $=0.912$ & ICV (Poland) & $=6.630$ \\
\hline & ISI (Dubai, UAE & $=0.829$ & РИНЦ (Russia & $=0.156$ & PIF (India) & $=1.940$ \\
\hline & GIF (Australia) & $=0.564$ & ESJI (KZ) & $=8.716$ & IBI (India) & $=4.260$ \\
\hline & JIF & $=1.500$ & SJIF (Morocce & $=5.667$ & OAJI (USA) & $=0.350$ \\
\hline
\end{tabular}

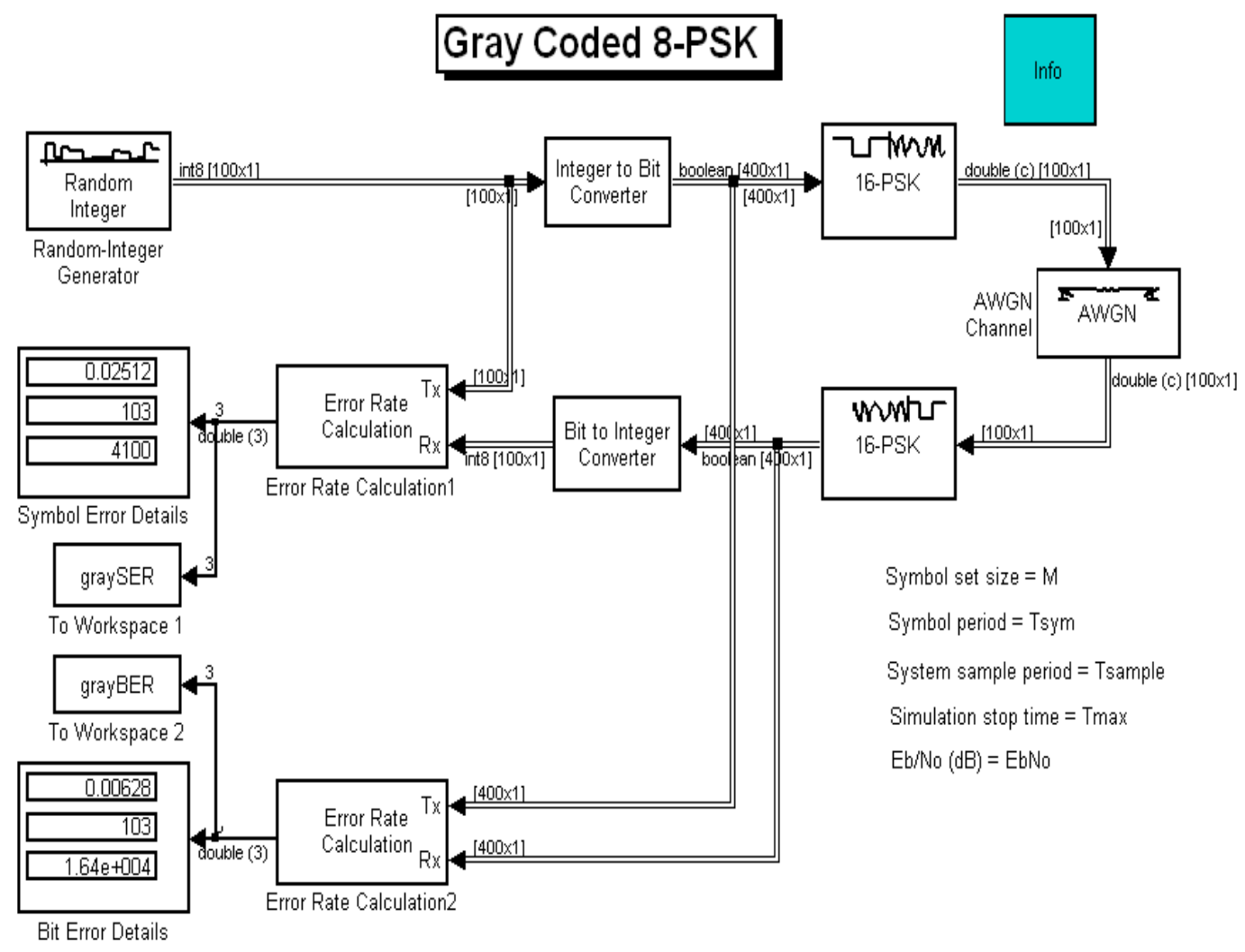

Figure 1. NC model by the Gray method using MPSK modulation

If the bits are allocated according to the symbols according to the binary sequence shown in Figure $2 a$, then some character errors will always produce two (or more) bit errors, even with a significant signal-tonoise ratio. For non-orthogonal schemes, such as MPSK, the code for converting binary symbols to M-

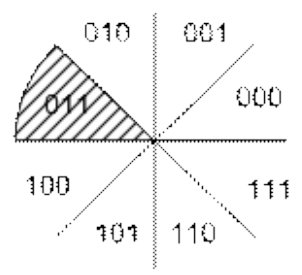

ary is often used, such that binary sequences corresponding to neighboring symbols (phase shifts) differ by a single bit position; Thus, when an error occurs in the M-ary symbol, the probability is high that only one of the $\mathrm{k}$ arrived bits is erroneous.



Figure 2. Areas of solution in the MPSK signaling space: $a$ ) in binary coding; $b$ ) Gray encoding.

The code providing this property is Gray code [2]; Figure 2, $b$ for the octal scheme PSK shows the bit allocation by symbols using the Gray code. It can be seen that adjacent symbols are distinguished by a single bit. Therefore, the probability of the appearance of a multi-bit error with a given character error is significantly smaller than the non-coded distribution of bits shown in Fig. 2a.

The implementation of such a Gray code is one of the rare cases in digital communication, when a certain benefit can be obtained without the attendant shortcomings. The Gray code is just an assignment that does not require special or additional schemes.

It can be shown [3] that if you use Gray's code, the error probability will be as follows.

$$
P_{B} \approx \frac{P_{E}}{\log _{2} M} \approx \frac{2 Q\left[\sqrt{\frac{2 E_{s}}{N_{0}}} \sin \left(\frac{\pi}{M}\right)\right]}{\log _{2} M}
$$

here the function $Q(x)$ is called the Gaussian error integral, $E_{s} / N_{0}$ is the ratio of the symbol energy to the spectral noise density.

The function $Q(x)$ is defined as follows: 


\begin{tabular}{|c|c|c|c|c|c|c|}
\hline \multirow{4}{*}{ Impact Factor: } & ISRA (India) & $=3.117$ & SIS (USA) & $=0.912$ & ICV (Poland) & $=6.630$ \\
\hline & ISI (Dubai, UAE & $=0.829$ & РИНЦ (Russia & $=\mathbf{0 . 1 5 6}$ & PIF (India) & $=1.940$ \\
\hline & GIF (Australia) & $=0.564$ & ESJI (KZ) & $=8.716$ & IBI (India) & $=4.260$ \\
\hline & JIF & $=1.500$ & SJIF (Morocco & $=5.667$ & OAJI (USA) & $=0.350$ \\
\hline
\end{tabular}

$$
Q(x)=\frac{1}{\sqrt{2 \pi}} \int_{x}^{\infty} \exp \left(-\frac{u^{2}}{2}\right) d u .
$$

The transmission of BPSK and QPSK signals has the same bit error probability.

Formula (1) proves that the probability of symbolic errors of these schemes is different. For BPSK modulation, $P_{E}=P_{B}$, and for QPSK $P_{E} \approx 2 P_{B}$.

\section{Probability of error for high-precision iterative code (HPIC)}

HPICs are formed by parallel cascading of two or more components of systematic codes. The transmitted data is mixed before encoding by each of the constituent codes using the interleavers included in the encoder. The channel can only transmit the original sequence and the test outputs of each of the encoders. As a result, the total code rate of the HPIC when using component codes at a rate of $1 / 2$ turns out to be $R=1 /(C+1)$, where $\mathrm{C}$ is the number of constituent encoders. When constructing the HPIC encoder, two identical recursive systematic convolutional (RSC) encoders are used.

The HPIC decoder is a cascade connection of two elementary decoders, two interleavers and two deinterleivers that perform the restoration of the original (before interleaving) symbol order. The decoder has a single output that the output components are soft decisions with respect to decodable bits, and the logarithm of the likelihood ratio (LLR-log-likelihood ratio) is usually used to represent soft decisions, the sign of which determines the decoded bit value (negative value corresponds to zero, positive value to one), and the module is the reliability of this value.

The logarithm of the likelihood ratio $L\left(u_{k}\right)$ for the information symbol $u_{k}$, as its name implies, is defined as follows:

$$
L\left(u_{k}\right)=\ln \left[\frac{P\left(u_{k}=+1\right)}{P\left(u_{k}=-1\right)}\right],
$$

where $P\left(u_{k}=m\right) \quad-$ is the probability that $u_{k}=m(m= \pm 1)$.

The operation principle of the HPIC decoder consists in performing several decoding iterations, for the first of which there is no a priori information at the input of the decoder of the first constituent code, i.e. it generates an estimate of the information bits using only the sequence received from the channel.

Further from the received estimation the socalled external information allocated, determined by an exception from an estimation of decoded symbols of the a priori information is allocated (on the first iteration the a priori information is equal to zero) and the systematic symbols received from the channel:

$$
L_{e}\left(u_{k}\right)=L\left(u_{k} \mid \bar{y}\right)-L_{C} y_{k s}-L\left(u_{k}\right),
$$

where $L_{C}$ determines the reliability of the channel (for the channel with AWGN $L_{C}=2 / \sigma^{2}$, where $\sigma^{2}$ is the noise variance).

Then, the decoder of the second code uses this external information as a priori to obtain its own information bit estimate. At the second iteration, the first decoder again processes the received sequence from the channel, but with the a priori information generated from the second decoder evaluation at the first iteration, this additional information allows the first decoder to obtain a more accurate estimate of the decoded bits then used by the second decoder as a priori.

In HPIC decoders, algorithms such as MAP (Maximum A Posteriori) [4], Log-MAP [5], MaxLog-MAP [6,7], SOVA (Soft Output Viterby Algorithm) [8] can be applied.

Knowing the complexity of implementing decoding methods for constituent codes $N_{\text {cocm }}$, one can estimate the complexity of decoding the whole HPIC:

$$
N_{\text {ВИК }}=I \cdot N_{\text {cocm }} \cdot C \text {, }
$$

where $\mathrm{I}$ is the number of decoding iterations; $\mathrm{C}$ is the number of constituent codes.

For an analytical evaluation of the HPIC efficiency, one can use the expression for the additive bound of the bit error probability of the block code

$$
P_{b} \leq \sum_{i=d}^{N} \frac{w_{i}}{L} P_{i}
$$

where $N$ is the length of the code block; $L$ is the number of block information symbols; $d$ is the minimum code distance; $w_{i}$ is the total information weight of all codewords of weight $i ; \quad \mathrm{b} P_{i}$ is the probability of choosing an incorrect codeword, which differs from the correct one in $i$ positions.

For a HPIC with a code rate $R=1 / 2$, consisting of two identical encoders with a constructive length $K$ and an interleaver of length $L$, the length of the code block will be $N=2(L+K-1)$.

Given that the total information weight wi of all codewords of weight $i$ is $w_{i}=w_{i}=\tilde{w}_{i} N_{i}\left(\tilde{w}_{i}\right.$ - average information weight of codewords of weight $i ; N_{i}-$ total number of codewords of weight $\mathrm{i}$ ), expression (6) looks like this:

$$
P_{b} \leq \sum_{i=d}^{N} \frac{\tilde{w}_{i} N_{i}}{L} P_{i}
$$

When calculating the boundary (7), they are often limited only by the first term, which approximates the probability of a bit error at medium and high values of the signal-to-noise ratio:

$$
P_{b} \approx \frac{\tilde{w}_{d} N_{d}}{L} P_{d}
$$

For example, consider the efficiency of a HPIC with a code rate $R=1 / 2$ obtained from two identical 


\begin{tabular}{|c|c|c|c|c|c|c|}
\hline \multirow{4}{*}{ Impact Factor: } & ISRA (India) & $=3.117$ & SIS (USA) & $=0.912$ & ICV (Poland) & $=6.630$ \\
\hline & ISI (Dubai, UAE & $=0.829$ & РИНЦ (Russia & $=\mathbf{0 . 1 5 6}$ & PIF (India) & $=1.940$ \\
\hline & GIF (Australia) & $=0.564$ & ESJI (KZ) & $=8.716$ & IBI (India) & $=4.260$ \\
\hline & JIF & $=1.500$ & SJIF (Morocco & $=5.667$ & OAJI (USA) & $=0.350$ \\
\hline
\end{tabular}

components of RSC codes with generating polynomials $g_{0}=37_{8}$ and $g_{1}=21_{8}$ and a pseudo-random interleaver of length $L=65536$ bits.

This HPIC can be designated as $(37,21,65536)$. Since for $(37,21,65536)$ HPIC $d=6, \widetilde{w}_{d}=2, \quad N_{d}=3$
[53], the expression (7) for the channel with AWGN takes the form

$$
P_{b}=\frac{2 \cdot 3}{65536} Q\left(\sqrt{6 \frac{E_{b}}{N_{0}}}\right)
$$

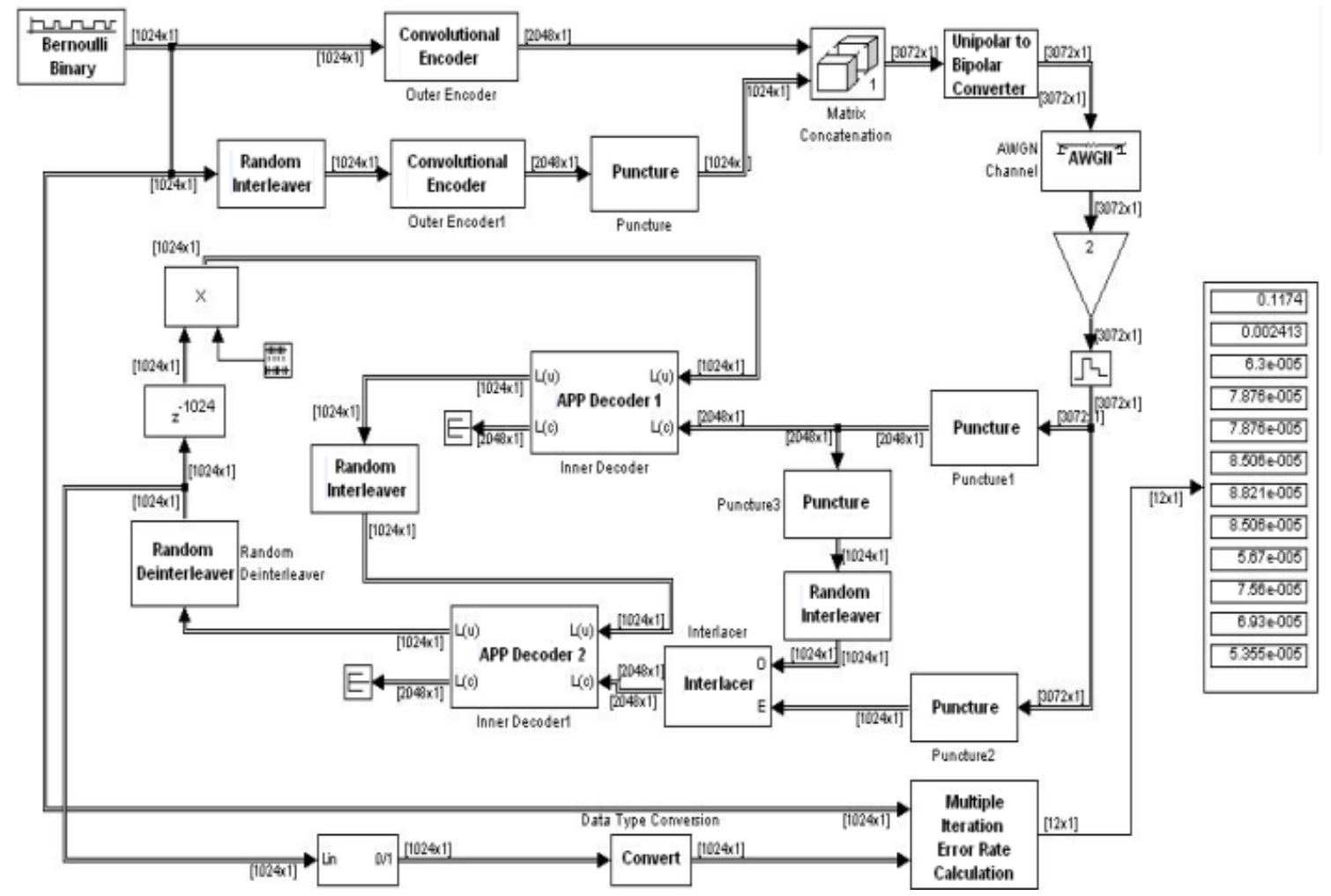

Figure 3. Simulation model of parallel-cascade high-precision coding and iterative decoding

Figure 3 shows an imitation model of parallelcascade high-precision coding and iterative decoding. This model allows modeling of HPIC encoding and decoding processes.

The model consists of the following blocks:

- a source of digital signals (Bernoulli Binary), which generates a sequence of zeros and ones;

- convolutional encoders of recursive systematic convolutional codes (Convolutional Encoder), which encodes interleaved data, this allows reducing the number of low-weight code words that determine the efficiency of a HPIC at a high level of noise in the channel;

- high-precision iterative decoders (APP Decoder), decoding bits based on the definition of a posteriori probability (APP - a posteriori probability);

- randominterleavers (Random Interleaver), mixing data before encoding;

- deinterleavers (Random Deinterleaver), carrying out the restoration of the original (before interleaving) the order of symbols;

- The interlaceer (Interlacer) interleaves the binary data when it arrives at the second decoder
HPIC (APP Decoder);

- The model of the channel with the additive white Gaussian noise (AWGN Channel) changes the ratio $E_{b} / N_{0}$. In the settings of this block, the number of information bits per character and the duration of the symbol in seconds are indicated.

The modulation was phase shift keying with the number of positions $M=2$ (2-PSK or 2-FM). Sequences are combined into packets of 1024 bits, after encoding, respectively, the length of the packet will be approximately 2048 bits.

\section{RESULTS AND DISCUSSION}

Figure 4 shows the HPH simulation - the error probability per bit (BER) versus the signal-to-noise ratio $\left(E_{b} / N_{0}\right)$ using the Gray code. The input signal is an integer from 0 to $\mathrm{M}-1$, where $\mathrm{M}$ is the modulation level or the alphabet size, produces at the output complex phase units in phase space 0 and $2 \pi(M-1) / M$.

The efficiency of noise-immune encoding is determined by the following formula: 


\begin{tabular}{|c|c|c|c|c|c|c|}
\hline \multirow{4}{*}{ Impact Factor: } & ISRA (India) & $=3.117$ & SIS (USA) & $=0.912$ & ICV (Poland) & $=6.630$ \\
\hline & ISI (Dubai, UAE & $=0.829$ & РИНЦ (Russia & $=\mathbf{0 . 1 5 6}$ & PIF (India) & $=1.940$ \\
\hline & GIF (Australia) & $=0.564$ & ESJI (KZ) & $=8.716$ & IBI (India) & $=4.260$ \\
\hline & JIF & $=1.500$ & SJIF (Morocco & $=5.667$ & OAJI (USA) & $=0.350$ \\
\hline
\end{tabular}

$$
G\left(\text { ББ) }=\left(\frac{E_{b}}{N_{0}}\right)_{\text {без кодирования }} \text { (дБ) }-\left(\frac{E_{b}}{N_{0}}\right)_{\text {скодированием }}\right. \text { (дБ) }
$$

To evaluate the efficiency of the $\mathrm{PC}$, the ratio $E_{b} / N_{0}$ of the energy per bit is compared to the noise power spectral density in the noise-immune coding system and in the base system without noise-immune coding, and the difference in $E_{b} / N_{0}$ values is determined for a given error probability.

This difference, measured in decibels and called EVC, can be used to compare different codes [9].

Experiments were also carried out in the case of the use of convolutional and block codes in the imitation coding model by the Gray method.

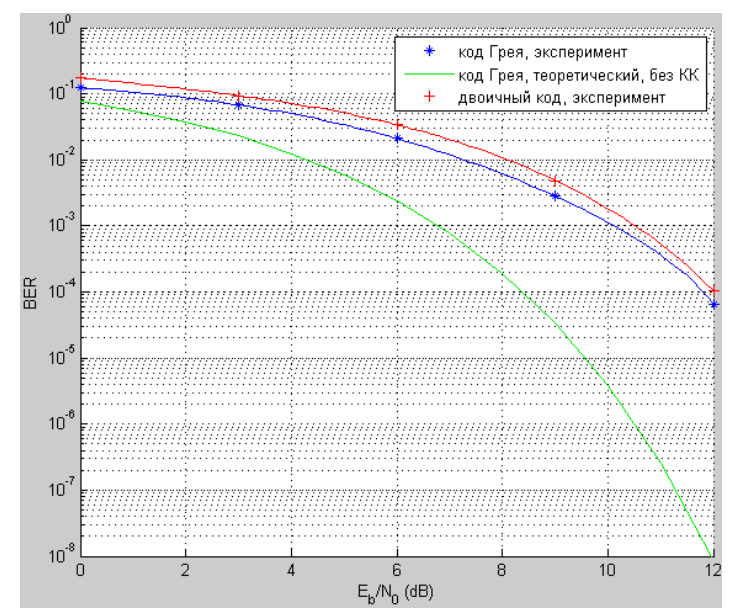

Figure 4. Dependence of the error probability on the bit on the signal-to-noise ratio of the Gray code

Figure 5 shows that the smallest $E_{b} / N_{0}$ ratio in the entire study interval in the convolutional coding (CC) of the Gray code, decoding bits based on soft decisions (SD) with 2-PSK, after it - convolutional code with 2-PSK, which The decoder works with a hard decision (HD).

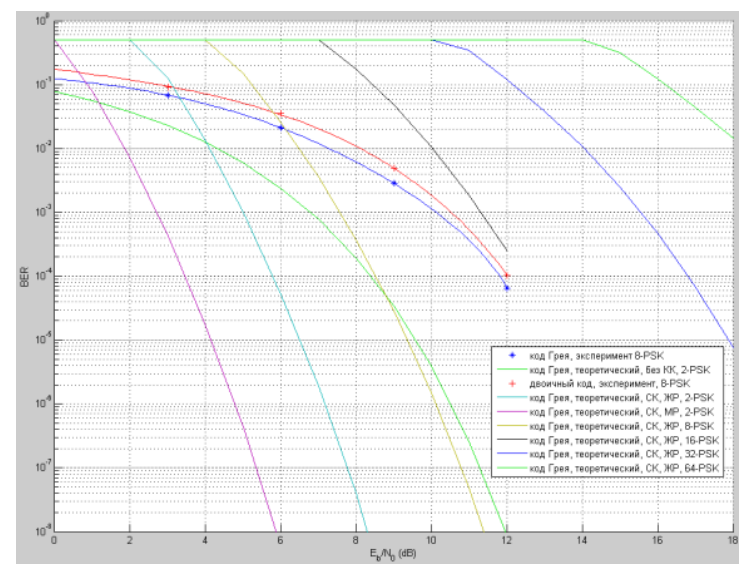

Figure 5. Characteristics of the BER for the Gray code using convolutional coding and multi-level phase shift keying, parameters of the Convolutional code (7, [171 133]).

For block coding (Fig. 6), the smallest $E_{b} / N_{0}$ ratio in the block coding $(\mathrm{BC})$ of the Gray code that the decoded bits appear on the basis of the MP with 4PSK, thereafter the case of block coding of the Gray code from the LCR of the decoder at 2-PSK.

The results of the study. IR decoding is an iterative process, during which two ISK decoders with a soft output exchange values of estimates of external probabilities [10, 11, 12].

Usually, 8-10 iterations are enough for changes in the estimates of decoded symbols to become insignificant, further iteration of the decoder practically does not lead to a decrease in the probability of error. One way to reduce the probability of error is to use high-precision iterative decoding (HPIDc).

For the simulation model shown in Fig. 3, the following values are selected for parallel-cascade high-precision encoding and iterative decoding codec parameters: 


\begin{tabular}{|c|c|c|c|c|c|c|}
\hline \multirow{4}{*}{ Impact Factor: } & ISRA (India) & $=3.117$ & SIS (USA) & $=0.912$ & ICV (Poland) & $=6.630$ \\
\hline & ISI (Dubai, UAE & $=0.829$ & РИНЦ (Russia & $=0.156$ & PIF (India) & $=1.940$ \\
\hline & GIF (Australia) & $=0.564$ & ESJI (KZ) & $=8.716$ & IBI (India) & $=4.260$ \\
\hline & JIF & $=1.500$ & SJIF (Morocce & $=5.667$ & OAJI (USA) & $=0.350$ \\
\hline
\end{tabular}

1) the number of bits in the information packet is $1024 ; 2)$ type of data transmission signal and type of reception - signal with 2-PSK, coherent reception;
3) the number of iterations of the HPIC-8 decoding process;

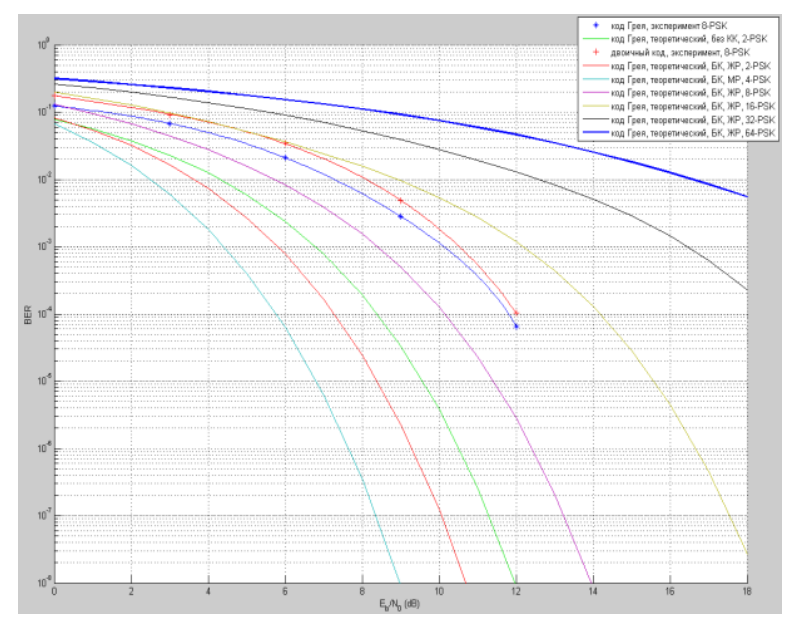

Figure 6. Characteristics of the BER for the Gray code using block coding and multilevel phase shift keying, parameters of the block code $n=7, k=4, d_{\min }=5$

4) HPIC parameters: code type - parallel concatenated code with two identical compound codes; the speed of the code is $1 / 2$;

5) parameters of compound codes: code type - binary perforated recursive convolutional code; code speed - 2/3; The parameters of the HPIC: $(33,31$, 77777)

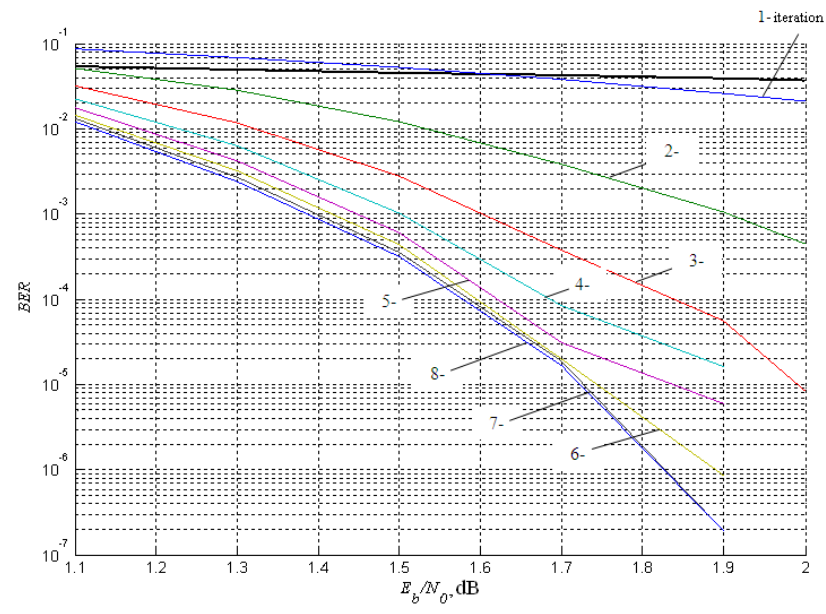

Figure 7. Characteristics of BER for HPIC using in the recursive systematic convolutional codes and 8 iterations with 2-PSK parameters $n=7, k=4, d_{\text {min }}=5$

IC decoding is an iterative process, during which two decoders of the iterative convolutional code (ICC) with a soft output are exchanged by values of estimates of external probabilities.

Usually, 8-10 iterations are enough for changes in the estimates of decoded symbols to become insignificant, further iteration of the decoder practically does not lead to a decrease in the probability of error. One way to reduce the probability of error is to use high-precision iterative decoding (HIDc).
Figure $8 a$ and $8 b$ shows the simulation results, depending on the number of iterations in the bit and block transmission structures.

For the working channel used, a channel with additive white Gaussian noise and binary phase modulation is selected. Initialization of the random number generator: $\mathrm{kst}=11100$.

Application: in digital terrestrial and satellite TV DVB-T2/T4, DVB-S/S2 high-precision iterative decoder (HIDc). 


\begin{tabular}{|c|c|c|c|c|c|c|}
\hline \multirow{4}{*}{ Impact Factor: } & ISRA (India) & $=3.117$ & SIS (USA) & $=0.912$ & ICV (Poland) & $=6.630$ \\
\hline & ISI (Dubai, UAE & $=0.829$ & РИНЦ (Russia & $=0.156$ & PIF (India) & $=1.940$ \\
\hline & GIF (Australia) & $=0.564$ & ESJI (KZ) & $=8.716$ & IBI (India) & $=4.260$ \\
\hline & JIF & $=1.500$ & SJIF (Morocce & $=5.667$ & OAJI (USA) & $=0.350$ \\
\hline
\end{tabular}

The length of the code block: 3008; We change the number and increase the length of the information part of the block to: 1504; Code speed: 1/2; The number of decoding iterations is increased to: 10 .

S/N Ratio: $E_{s} / N_{0}=-1,32 \mathrm{~dB}\left(E_{b} / N_{0}=1,7 \mathrm{~dB}\right)$.
In total, 1000160 bits and 665 blocks are decoded. To decode the constituent codes, a max-logMAP algorithm was used.

\section{Result:}

Number of erroneously decoded bits 0 . Probability error $0.00 \mathrm{e}-000$.

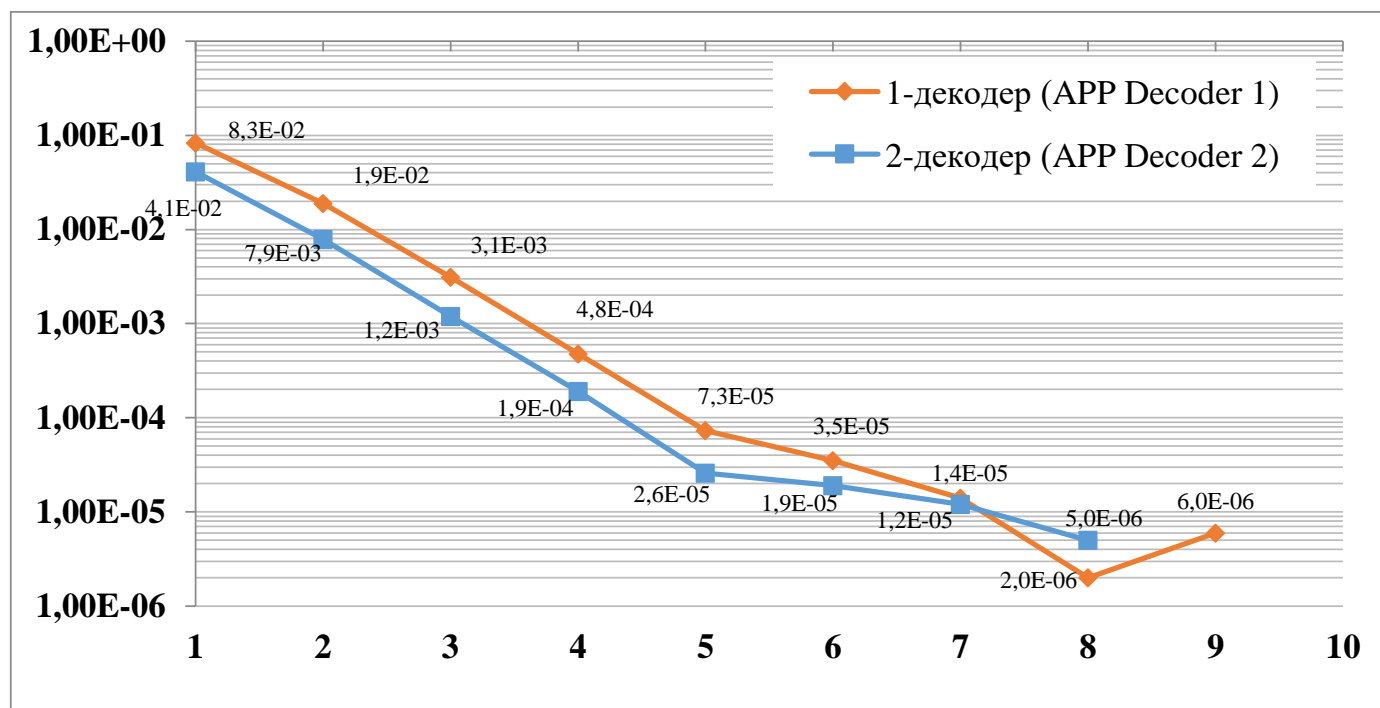

Figure $8 a$. The result of the error probability in bits, $P_{b}$, on the number of iterations of the high-precision iterative code with the parameter $(33,31,11100)$.

Number of erroneously decoded blocks 0 . Probability error $0.00 \mathrm{e}-000$.

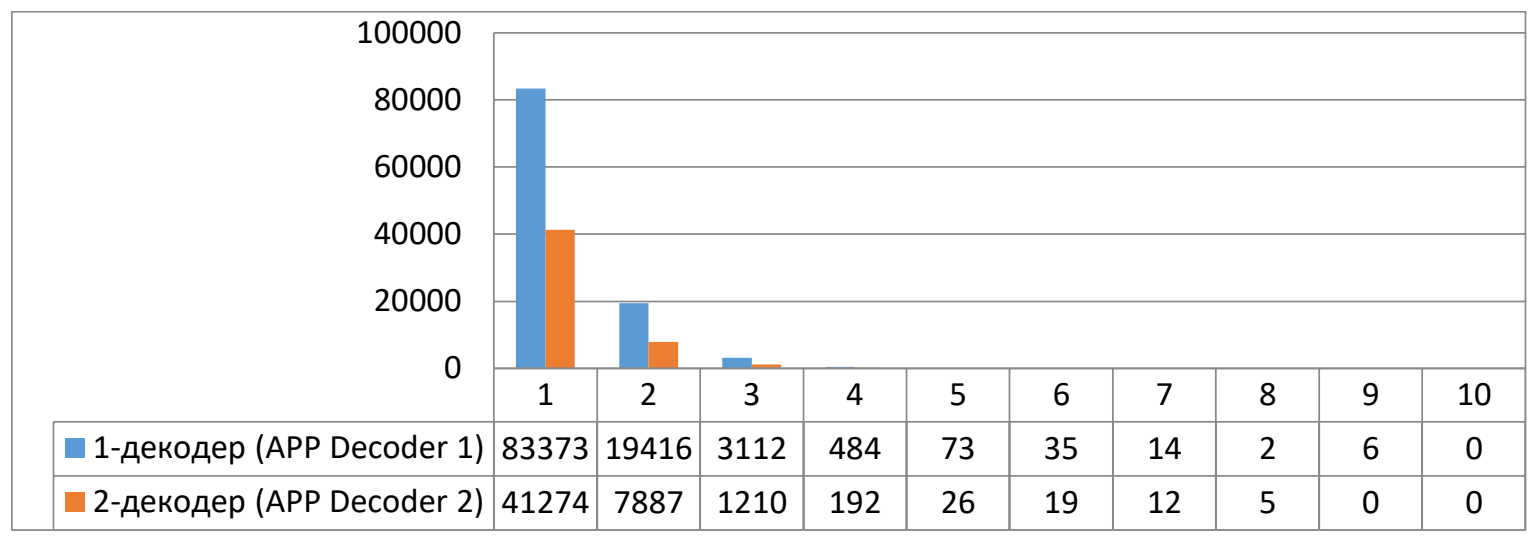

Figure $8 b$. The result of the dependence is the number of errors in bits $N$, on the number of iterations.

From the characteristic shown in Figure 4, it is seen that for a system requiring an immunity in the order of $10^{-7}$, approximately $13.5 \mathrm{~dB}$ of energy is required. In the experiment, it was found that to achieve noise immunity $P_{b}=10^{-4}$ with the use of the Gray code, a signal-to-noise ratio of about $12.3 \mathrm{~dB}$ is required.

This value is higher than the average for the dependence of energy and noise immunity in digital information transmission systems. In modern digital systems, to achieve this index $\left(10^{-4}\right)$, an average of 4.2-5.0 dB of energy is required. In this context, 12.3 $\mathrm{dB}$ shows an excessive consumption of useful power to obtain the error probability $P_{b}=10^{-4}$. From the simulation result of the HPIC shown in Figure 7, it is seen that to achieve noise immunity $P_{b}=10^{-4}$, for example, at the $3 \mathrm{rd}$ iteration, only $1,85 \mathrm{~dB}$ is needed, and on the 8 th $-1,58 \mathrm{~dB}$. Using formula (10), we 


\begin{tabular}{|c|c|c|c|c|c|c|}
\hline \multirow{4}{*}{ Impact Factor: } & ISRA (India) & $=3.117$ & SIS (USA) & $=0.912$ & ICV (Poland) & $=6.630$ \\
\hline & ISI (Dubai, UAE & $=0.829$ & РИНЦ (Russia & $=\mathbf{0 . 1 5 6}$ & PIF (India) & $=1.940$ \\
\hline & GIF (Australia) & $=0.564$ & ESJI (KZ) & $=8.716$ & IBI (India) & $=4.260$ \\
\hline & JIF & $=1.500$ & SJIF (Morocco & $=5.667$ & OAJI (USA) & $=0.350$ \\
\hline
\end{tabular}

determine the energy gain of the coding to achieve $P_{b}=10^{-4}$ :

$$
\begin{gathered}
G\left(\text { ББ) }=\left(\frac{E_{b}}{N_{0}}\right)_{\text {withoutcoding }} \text { (дБ) }-\left(\frac{E_{b}}{N_{0}}\right)_{\text {withenooding }}\right. \text { (дБ) } \\
12,3 \text { (дБ) }-1,85 \text { (дБ) }=10,45 \text { (дБ)! }
\end{gathered}
$$

\section{CONCLUSIONS}

When using iterative codes, you can achieve higher noise immunity of the system. However, their use is limited by the time delay of the decoding, due to the fact that it is impossible to decode part of the packet until it arrives completely (in other codes this is possible). As can be seen from the result, obtained at the output of the simulation model of parallelcascade high-precision coding and iterative decoding (Figure 3), based on the developed algorithm, it is possible to obtain an energy gain in the range of 0.5 -
$14 \mathrm{~dB}$ in comparison with other of the original decoders. In this case, the algorithm of high-precision iterative decoding with smaller $E_{b} / N_{0}$ ratios begins to coincide with the solution of the optimal decoder. Analysis of the evaluation of the efficiency of the developed algorithm showed that, in comparison with convolutional encoders, using the iterative algorithms, the bit and block error probabilities are reduced (Figure 7) to previously impossible ultra-low values of $E_{b} / N_{0}$, and the algorithm allows obtaining an energy gain in comparison with convolutional codes. The obtained algorithm can work with higher coding rates, different from $r=1 / 2$, which allows to reduce code redundancy and increase the information content of the output sequence, without reducing the system noise immunity.

\section{References:}

1. Abduazizov, A. A., \& Atadjanov, S. S. (2009, October 23-24). Virtual stand for the study of channel codecs in digital information transmission systems. International Conference Innovation - 2009. Tashkent, Uzbekistan.

2. Van Trees, H. L. (1968). Detection, Estimation, and Modulation Theory. Part 1, John Wiley \& Sons, Inc., New York.

3. Lindsey, W. C., \& Simon, M. K. (1973). Telecommunication Systems Engineering. Prentice-Hall, Inc. Englewood Cliffs, N. J.

4. Bahl, L. R., Cocke, J., Jelinek, F., \& Raviv, J. (1974, March). Optimal Decoding of Linear Codes for Minimizing Symbol Error Rate. IEEE Trans. Inf. Theory, Vol. 20, pp. 284-287.

5. Robertson, P., Villebrun, E., \& Höher, P. (1995, June). A Comparison of Optimal and SubOptimal MAP Decoding Algorithms Operating in the Log Domain. in Proc. of the Intern. Conf.On Commun. (Seattle, US). pp. 10091013.

6. Erfanian, J., Pasupathy, S., \& Gulag, G. (1994). Reduced complexity symbol detectors with parallel structures for ISI channels. IEEE Trans. On Commun., Vol. 42, pp. 1661-1671.

7. Koch, W., \& Baier, A. (1990, December). Optumum and sub-Optumum detection of coded data disturbed by time-varying intersymbol interference. IEEE Globecom. pp. 1679-1684.

8. Hagenauer, J., \& Hoeher, P. (1989). A Viterby algorithm with soft-decision outputs and its applications. in IEEE Globecom. pp. 1680-1686.

9. Lokshin, B. A. (2001). Digital broadcasting: from studio to TV viewer. (pp. 77-80). Moscow: Company Cyrus Systems.

10. Berrou, C., Glavieux, A., \& Thitimajshima, P. (1996). Near Shannon Limit Error-Correcting Coding and Decoding: Turbo-Codes. IEEE Transactions on Information Theory, V. 44, № 10, pp. 1064-1070.

11. Kozlov, A. V. (2007). Decoding of LDPC codes in a discrete flash memory channel. ICS, No. 5 (30), pp. 31-35.

12. Belogolovy, A. V., \& Kruk, E. A. (2005). Multithreshold decoding of codes with low density of checks for parity. ICS, № 1(14), pp. 25-31 